Hemisphere function and

\section{immedlate memory}

STUART J.DIMOND, University College of South Wales, Cardiff, Wales

Series of digits were directed to one hemisphere or the other using a divided visual field technique. When two series of digits were directed simultaneously to the same hemisphere immediate memory performance was better than when both series were directed to different hemispheres. No significant difference was observed between the performance of one hemisphere and the other when both the series were directed to only one hemisphere.

Immediate memory has been studied previously by presenting two series of digits simultane ously to different ears (Broadbent, 1952). In other experiments by the same author one series of digits has been presented to the ear, the other to the eye. The object of the experiment described here was to present the $S$ simultaneously with two series of digits, one series to one hemisphere and the other to the same or to a different hemisphere. The necessity for intercommunication between one hemisphere and the other and the time lags introduced by cross-talk between the hemispheres would be expected to result in a reduction of the efficiency of the memory process when the information is shared between the hemispheres. The experiment was designed to investigate this possible reduction in efficiency and any facilitation of performance when both streams of digits are directed to a single hemisphere.

A number of investigators have reported the superiority of one ear over the other on immediate memory tasks (Kimura, 1961;
Bryden, 1963). Related to this, the suggestion arises that there are differences in immediate memory performance between one hemisphere and the other. A second aim of this experiment, therefore, was to examine immediate memory when both series of digits were directed to separate hemispheres, in order to compare the efficiency of performance in relation to both the right and the left hemisphere.

The $S$ was confronted with a four-choice display of four screens measuring $23 \mathrm{~cm}$ square. The screens were placed at a distance of $50 \mathrm{~cm}$ from the S's eyes. The digits to be remembered were presented at each of these four screens. The digits, $20 \mathrm{~cm}$ high, were back-projected onto these screens, using automatic loading projectors. These projectors were synchronized and controlled by a series of switches.

The apparatus was constructed in such a way that signals were directed only to the temporal or nasal retina of each eye. The S's visual field was divided by two partitions which ran parallel to the S's line of vision. One partition was inserted between the first and second screen and the S's right eye, the other between the third and the fourth window and the $S$ 's left eye. The partitions directed signals from each screen to only one of the hemiretinae. Signals from the first screen were directed to the right nasal area, from the second to the left temporal, from the third to the right temporal, and from the fourth to the left nasal area. This situation is represented diagrammatically in Fig. 1 . Each partition was extended parallel to the eye at right angles for a distance of 2 in. to ensure that the $S$ saw only the screen he was intended to see using a particular retinal

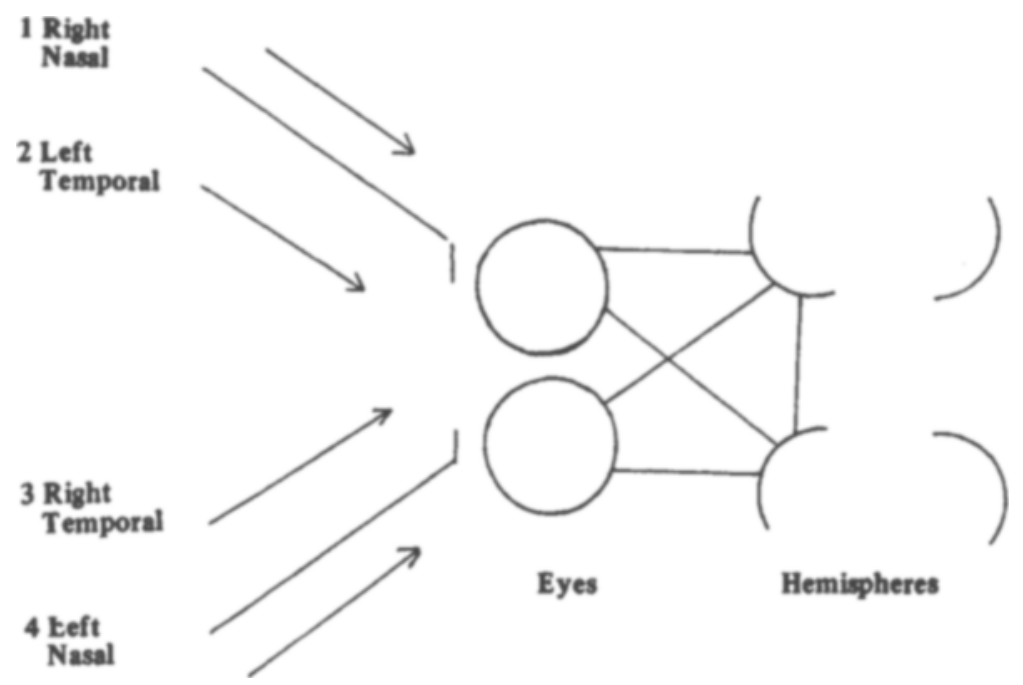

area. A fixation point was provided in the center of the apparatus by a pilot light (L.E.S. pilot bulb, 12-14 V, 75 W). Behind this pilot light a small aperture was cut which allowed the $E$ to observe the $S$ 's eye movements.

Twenty Ss were used in this experiment. Each $S$ was asked to write his name on a sheet of paper before the experiment began, and at the conclusion of the experiment the Ss completed the Humphrey-Oldfield Sinistrality Index. ${ }^{1}$ These procedures were carried out to assess the Ss' lateral preference. The Ss were right-handed, and all Ss showed a distinct right lateral preference. None of the Ss wore glasses or reported the presence of visual defects. Each $S$ was told that he would be shown a series of digits and was asked to remember them. The $S$ was asked to keep looking at the central fixation point. The $S$ was shown a series of six digits on one of the screens. The $S$ received four practice trials during which three digits appeared at one window and three at another. Ss failing to focus on the central fixation point after four trials were excluded from the rest of the experiment, and if at any time during the rest of the experiment the $S$ looked away from the central fixation point he was asked to refocus upon it.

In each condition of the experiment the $S$ received a series of six digits. In the first condition, all six were presented consecutively to one visual area. In the second condition, one series of three was presented to one visual area at the same time as another series of three digits was presented to another visual area. There were six combinations of double series. These were represented with equal frequency. The single and the double series of signals were given in a different mixed random order for each S. Digits were presented at the rate of one every $1.73 \mathrm{sec}$, each digit appearing on the screen for a period of $0.34 \mathrm{sec}$. At the conclusion of the experiment the Ss were given a recognition test in which 12 digits were presented for the same duration in random order at all four screens and the S's task was simply to identify one digit before being presented with the next.

The percentage of correct sequences recalled in the single series condition is presented in Table 1. There were no significant differences in the percentage recalled when each series of single digits was directed to different retinal areas and ipso facto to different cerebral hemispheres (Wilcoxon matched pairs test). The number of digits reversed in order was greatest in

Fig. 1. Schematic diagram of apparatus and visual pathways. 
value when the signals were presented to the right temporal area.

The results for the double series condition are presented in Table 2 . In other experiments in which two series are presented simultaneously to both ears, the Ss report all the signals on one ear before reporting those on the other. In the experiment described here, the Ss almost invariably reported the double series as a series of three pairs, the digit appearing to the left of the display being reported before that appearing to the right. Possibly the slow rate of signal presentation in the experiment explains the difference. When both series of digits were directed to the same hemisphere, a marked increase was observed in the number of digits recalled. This improvement in performance was found to be significant over the condition in which signals were directed to separate hemispheres beyond the .01 level (Wilcoxon matched pairs test). The number of digit reversals was found to be reduced when both series were directed to the single hemisphere. No difference was observed in performance when signals were directed to the right hemisphere rather than to the left hemisphere.

When both digit series were directed to a single hemisphere, the percentage of correct trials did not differ significantly from the single series control. When, however, signals were directed to different hemispheres, memory performance was found to be significantly impaired. In the final recognition test, all Ss were found to be highly accurate in the identification of the digits presented to them.

In assessing immediate memory performance in relation to the hemispheric structure of the brain, the results of this investigation suggest that immediate memory functions are bilaterally located. In the single series condition, significant differences were not observed in the performance on one hemisphere relative to another when both series were directed to the same hemisphere.

What was observed, however, was a marked deterioration in performance when one series of digits was directed to one

Table 1

Percentage Series Correct in Single Series Condition

\begin{tabular}{lcccc}
\hline $\begin{array}{l}\text { Retinal } \\
\text { Position }\end{array}$ & $\begin{array}{c}\text { Right } \\
\text { Nasal }\end{array}$ & $\begin{array}{l}\text { Left } \\
\text { Temporal }\end{array}$ & $\begin{array}{c}\text { 3 } \\
\text { Temporal }\end{array}$ & $\begin{array}{c}\text { Left } \\
\text { Nasal }\end{array}$ \\
\hline $\begin{array}{l}\text { Percentage } \\
\begin{array}{l}\text { Correct } \\
\text { Trials }\end{array}\end{array}$ & $89 \%$ & $89 \%$ & $92 \%$ & $90 \%$ \\
\hline \begin{tabular}{l} 
Reversals \\
\hline
\end{tabular} & $0 \%$ & $7 \%$ & $23 \%$ & $5 \%$ \\
\hline
\end{tabular}

Table 2

Percentage Correct in the Double Series Condition

\begin{tabular}{|c|c|c|c|c|}
\hline \multirow{2}{*}{$\frac{\text { Hemisphere }}{\text { Same Hemisphere }}$} & \multicolumn{2}{|c|}{ Retinal Position } & \multirow{2}{*}{$\frac{\text { Percentage }}{85 \%}$} & \multirow{2}{*}{$\frac{\text { Reversals }}{0 \%}$} \\
\hline & 1 Right + & $\begin{array}{l}2 \text { Left } \\
\text { Temporal }\end{array}$ & & \\
\hline & $\begin{array}{r}3 \text { Right }+ \\
\text { Temporal }\end{array}$ & $\begin{array}{l}4 \text { Left } \\
\text { Nasal }\end{array}$ & $84 \%$ & $5 \%$ \\
\hline \multirow[t]{4}{*}{ Different Hemisphere } & $\begin{array}{l}1 \text { Right }+ \\
\text { Nasal }\end{array}$ & $\begin{array}{l}3 \text { Right } \\
\text { Temporal }\end{array}$ & $60 \%$ & $15 \%$ \\
\hline & $\begin{array}{l}1 \text { Right } \\
\text { Nasal }\end{array}$ & $\begin{array}{l}4 \text { Left } \\
\text { Nasal }\end{array}$ & $52 \%$ & $17.5 \%$ \\
\hline & $\begin{array}{l}2 \text { Left } \\
\text { Temporal }\end{array}$ & $\begin{array}{l}3 \text { Right } \\
\text { Temporal }\end{array}$ & $75 \%$ & $7.4 \%$ \\
\hline & $\underset{\text { Temporal }}{2 \text { Left }}+$ & $\begin{array}{l}4 \text { Left } \\
\text { Nasal }\end{array}$ & $70 \%$ & $5 \%$ \\
\hline
\end{tabular}

hemisphere while at the same time another series of different digits was directed to the other. Two aspects of interhemispheric communication could be implicated here: (1) the delay in transmitting information from one hemisphere, and (2) possible queuing of information before interhemispheric transmission takes place. Both factors, in acting to delay the linking of the information from one series with that of the other, could be expected to cause a deterioration in performance.

There is little evidence to suggest that one particular hemisphere consistently directs its information to the other without carrying out an analysis of the information itself, little evidence, for example, that the right hemisphere consistently despatches information to the left without receiving reciprocal information in its place. It is possible to suggest, therefore, that interhemispheric rivalry plays a part in the observed memory deficit. Each hemisphere in receiving information could both store it and direct a template copy to the other hemisphere. The hemispheres, in sending different information through the intercommunicating system, would find themselves in competition with one another which would be expected to act in a disruptive fashion on the information which had to be stored and transmitted.

\section{REFERENCES}

BROADBENT, D. E. Listening to one of two synchronous messages. Journal of Experimental Psychology, 1952, 44,51-55.

BROADBENT, D. E. Successive responses to simultaneous stimuli. Quarterly Joumal of Experimental Psychology, 1956, 8, 145-152.

BRYDEN, M. P. Ear preferences in auditory perception. Joumal of Experimental Psychology, 1963, 65, 103-105.

KIMURA, D. Cerebral dominance and the perception of verbal stimuli. Canadian Joumal of Psychology, 1961, 15, 156-171.

$$
\text { NOTE }
$$

1. The author is greatly indebted to R. C. Oldfield for his help in making this index available. 